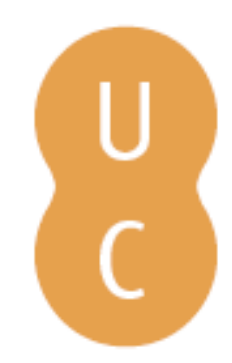

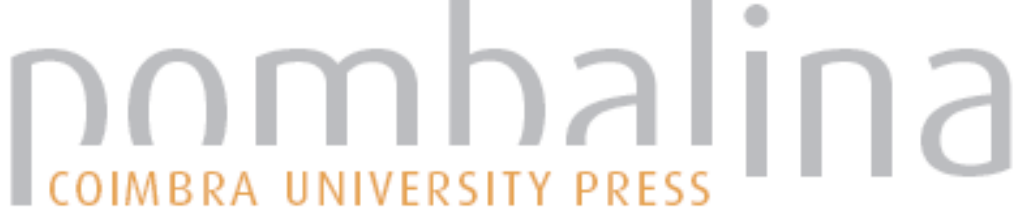

\section{República Islâmica do Irão}

\author{
Autor(es): $\quad$ Simão, Licínia
}

Publicado por: Imprensa da Universidade de Coimbra

URL

persistente: $\quad$ URI:http://hdl.handle.net/10316.2/38499

DOI: $\quad$ DOI:http://dx.doi.org/10.14195/978-989-26-0995-9_13

Accessed : $\quad$ 26-Apr-2023 11:22:08

A navegação consulta e descarregamento dos títulos inseridos nas Bibliotecas Digitais UC Digitalis, UC Pombalina e UC Impactum, pressupõem a aceitação plena e sem reservas dos Termos e Condições de Uso destas Bibliotecas Digitais, disponíveis em https://digitalis.uc.pt/pt-pt/termos.

Conforme exposto nos referidos Termos e Condições de Uso, o descarregamento de títulos de acesso restrito requer uma licença válida de autorização devendo o utilizador aceder ao(s) documento(s) a partir de um endereço de IP da instituição detentora da supramencionada licença.

Ao utilizador é apenas permitido o descarregamento para uso pessoal, pelo que o emprego do(s) título(s) descarregado(s) para outro fim, designadamente comercial, carece de autorização do respetivo autor ou editor da obra.

Na medida em que todas as obras da UC Digitalis se encontram protegidas pelo Código do Direito de Autor e Direitos Conexos e demais legislação aplicável, toda a cópia, parcial ou total, deste documento, nos casos em que é legalmente admitida, deverá conter ou fazer-se acompanhar por este aviso.

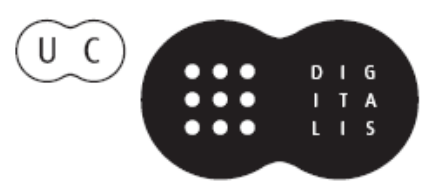




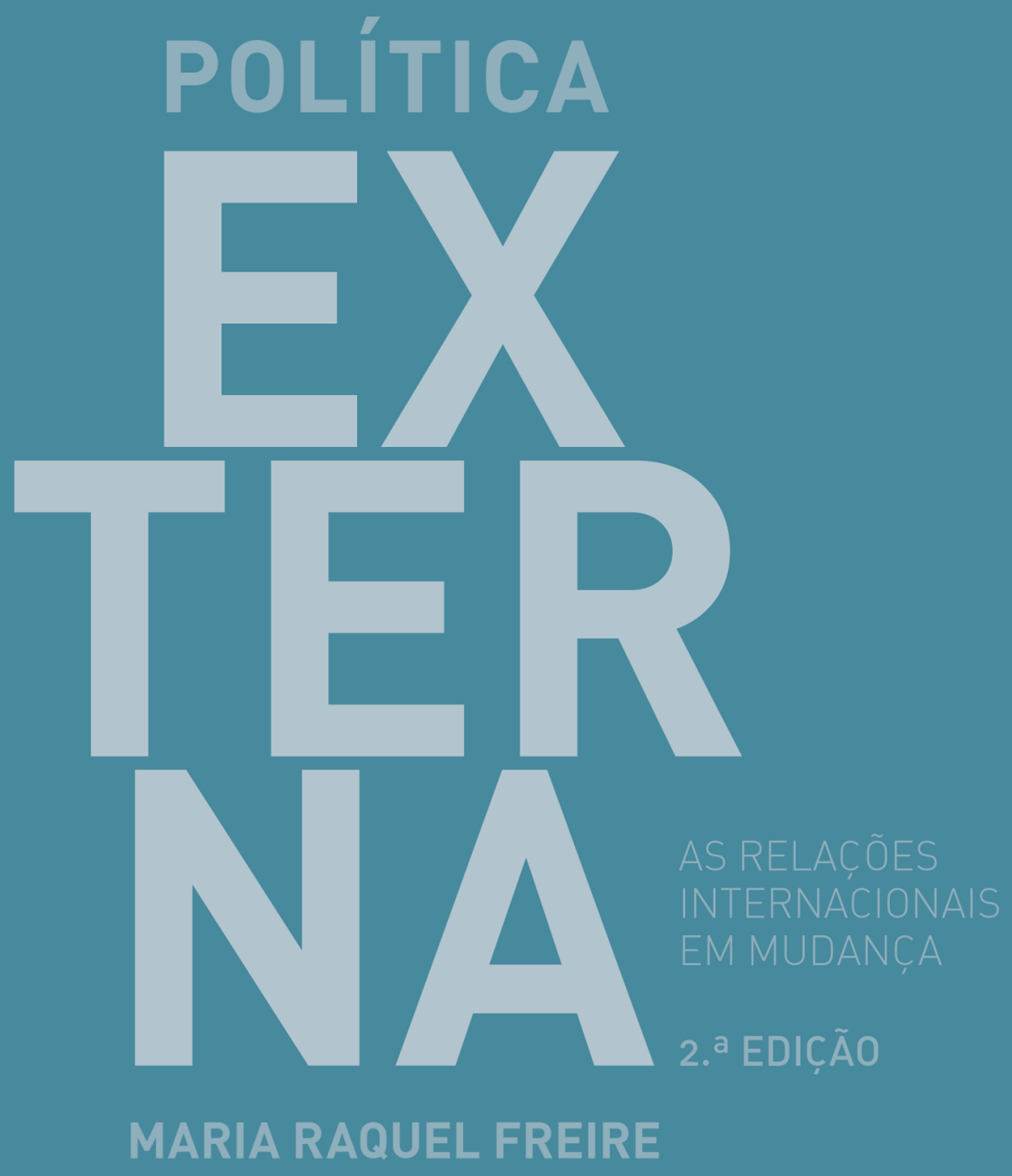

COORDENAÇÃO 


\section{CA P Í T UL O 13 \\ REP Ú B L I CA I S L ÂM I CA DO I R ÃO}

Licínia Simão

\section{Principais linhas da política externa iraniana: pragmatismo e ideologia}

O Irão ${ }^{111}$ apresenta um conjunto de princípios basilares na sua política externa que se mantiveram inalterados durante a sua longa história (Frye, 1996): um profundo pragmatismo, que visa assegurar os interesses geoestratégicos do país e a sua segurança; e uma dimensão ideológica, que permanece parte integrante da identidade, história e cultura iranianas (Ramazani, 2004). Assim, a política externa iraniana apresenta-se como sendo "caleidoscópica» (Ramazani, 1989: 211), ilustrando a constante fluidez dos arranjos políticos e das posições defendidas pelos líderes políticos e religiosos. A defesa primordial do interesse nacional iraniano, que historicamente inclui independência e segurança num contexto regional desfavorável, é, pois, o principal motor da definição de uma política externa flexível

111 Até 1935, a atual República Islâmica do Irão (RII) era conhecida pelo nome oficial de Pérsia. Por decisão do Xá Muhammad Reza, nesse ano, o país mudou a designação oficial para Irão e, depois de Revolução Islâmica de 1979, adotou o atual nome. Ao longo deste capítulo serão utilizadas as designações Irão e RII de forma aleatória. 
e pragmática. Tendo em conta a natureza estratégica e disputada da região do Golfo Pérsico e a presença de potências externas, os diferentes regimes em Teerão procuraram implementar uma política de equilíbrio (imparcialidade e não-alinhamento), que exigia equidistância. A decisão, em 1951, do Primeiro-ministro Muhammad Mosaddeq de nacionalizar a indústria petrolífera iraniana, então dominada pelos ingleses, e, mais tarde, o mote promovido pelo primeiro Líder Supremo, Aiatola Khomeini ${ }^{112}$, "Nem Oriente, nem Ocidente, mas a República Islâmica», são boas ilustrações desta abordagem.

Um outro aspeto central é a política de alianças e acomodação (Barzegar, 2010: 181). Esta combinação de escolhas táticas, aliando-se a atores estratégicos e procurado encontrar formas de acomodar, quer os seus interesses, quer os dos seus aliados, reforça a ideia de flexibilidade e fluidez na política externa iraniana. Embora as relações com os vizinhos sejam permanentemente tensas, depois da guerra Irão-Iraque e sob a liderança de Rafsanjani, foi visível uma aproximação às monarquias árabes do Golfo Pérsico, incluindo à Arábia Saudita, ilustrando a escolha pela acomodação de interesses regionais. Os líderes iranianos reconheceram que, sendo um estado Shi'ita motivado pela exportação da sua revolução religiosa, as relações regionais seriam inevitavelmente marcadas pela suspeição, mas reconheceram também que a falta de apoio que o Irão sentiu durante a guerra com o Iraque se deveu, em parte, à dimensão ideológica e poderia ser alterada, se esta fosse revista (Takeyh, 2009: 130-139). De forma semelhante, durante a presidência de Khatami e na atual presidência de Rouhani, são visíveis esforços para reconfigurar as relações, quer com os vizinhos, quer com os Estados Unidos da América (EUA) (Barzegar, 2010: 181; Takeyh, 2009: 196-204).

112 O Irão teve até hoje apenas dois Líderes Supremos: o Aiatola Ruhollah Khomeini (1979-1989) e o Aiatola Ali Khamenei (1989-). 
A organização política e a distribuição de poder entre diferentes elites são fatores centrais na definição de políticas externas. A estrutura governativa iraniana, criada pela Constituição de 1979, estabelece a par das estruturas seculares eleitas, como o Presidente da República ou o Parlamento nacional, estruturas religiosas não eleitas com vastos poderes de supervisão e decisão (ver gráfico abaixo). As responsabilidades pela política externa estão concentradas, oficialmente, na figura do Líder Supremo. É ele quem comanda as Forças Armadas (incluindo o Exército dos Guardiães da Revolução Islâmica) e o seu gabinete tem amplos poderes em matéria de segurança, defesa e política externa. O Conselho Supremo de Segurança Nacional foi estabelecido aquando da revisão constitucional de 1989 e funciona como o órgão decisório onde a política externa é efetivamente desenhada por consenso e sob supervisão do Líder Supremo. O Presidente mantém também poderes na formulação da política externa, devido à sua posição como chefe de governo. A par do Ministro dos Negócios Estrangeiros, cada Presidente procura imprimir um cunho pessoal nas opções de política externa mas, em última análise, as decisões finais devem refletir o equilíbrio de forças existente na sociedade e entre as elites políticas e religiosas do país.

As relações com os EUA são um tema central e permanente da política externa iraniana, como são também as relações no contexto regional do Médio Oriente. A preocupação em manter um equilíbrio de forças que garanta a segurança da nação Shi'ita, num contexto maioritariamente Sunita é outro fator central, definidor das suas opções estratégicas, nomeadamente nas suas relações com movimentos como o Hezbollah no Líbano ou as minorias Shi'itas no Iraque e no Afeganistão. Assim, tendo em conta os pilares e opções estratégicas da política externa iraniana, a análise que se segue procura ilustrar estas dinâmicas, colocando-as no contexto político doméstico e externo e identificando eventos centrais que marcaram a forma 
como o Irão se apresentou ao mundo ao longo do século $\mathrm{XX}$ e no início do século XXI.

Gráfico 1. Estrutura Governativa do Irão

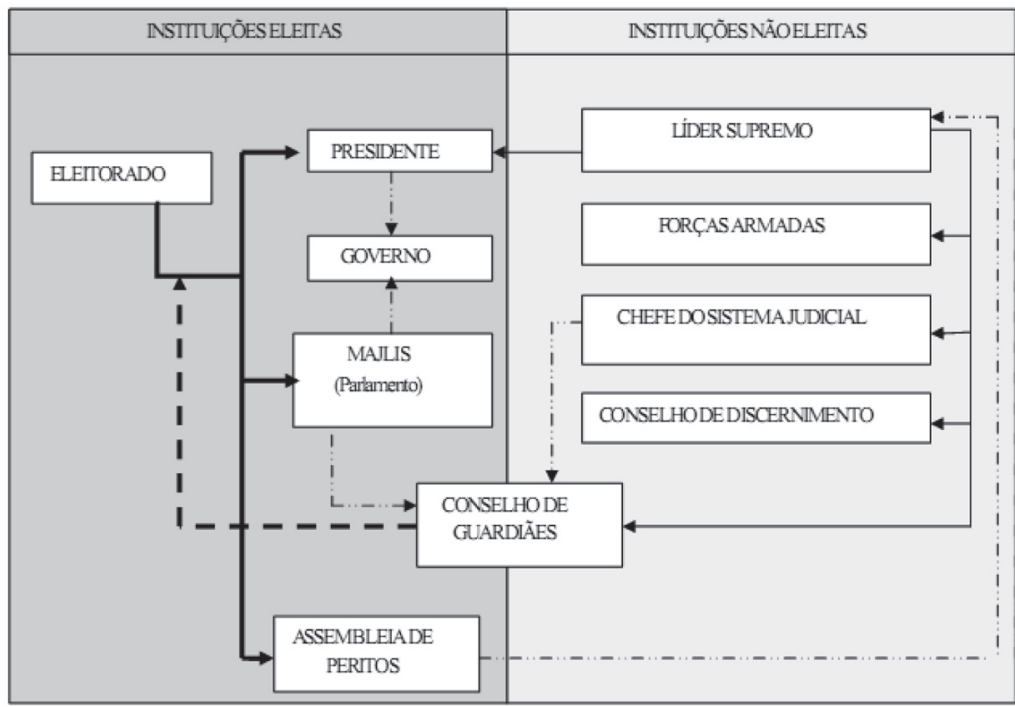

Legenda:

$\longrightarrow$ Eleição directa $-\rightarrow$ Veta Candidatos $\longrightarrow$ Controla $\rightarrow$ Nomeia ou aprova

Fonte: http://commons.wikimedia.org/wiki/File\%3ASchema_gvt_iran_ en.png

\section{Política externa na dinastia Pahlavi}

A revolução islâmica de 1979, que levou à deposição do Xá Muhammad Reza Pahlavi, foi motivada pelo descontentamento geral com as políticas autoritárias do Xá, nomeadamente a atuação da polícia secreta SAVAK, mas principalmente por um profundo sentimento nacionalista que via o país refém de interesses estrangeiros, liderados pelos EUA. O Golpe de Estado que levou ao poder o Xá Reza Pahlavi e deu início à dinastia Pahlavi, em 1921, foi não só em parte facilitado pelo envolvimento britânico, como permitiu a criação e 
desenvolvimento formal de um modelo de estado ocidental (Chehabi, 1998: 495). Os interesses britânicos no Irão remontam ao início do século XX, com a criação da Companhia Petrolífera Anglo-Persa ${ }^{113}$, que viria a ser um laço fundamental nas relações do Irão com o ocidente. Mais tarde, a 25 de agosto de 1941 e em plena Segunda Guerra Mundial, receando que a forte presença alemã no Irão se transformasse numa ameaça aos interesses ingleses e soviéticos na região, os dois países invadem o Irão, numa manobra militar e política que culminou na prisão e expulsão para o exílio do Xá Reza Pahlavi e a sua substituição pelo seu filho Muhammad Reza Pahlavi. Os motivos desta decisão britânico-soviética prenderam-se, oficialmente, com a necessidade de assegurar direitos de trânsito para as tropas aliadas, que procuravam derrotar os alemães na frente russa, mas refletiram também a vontade de proteger interesses britânicos, nomeadamente na exploração dos campos petrolíferos (Eshraghi, 1984: 37-38). Entre 1941 e o fim da Segunda Guerra Mundial, a presença de tropas estrangeiras no Irão foi uma realidade. Embora os Aliados tenham procurado assegurar ao Xá o respeito pela integridade territorial do país e a sua intenção de retirar completamente do seu território, depois de terminada a guerra, os primeiros ecos da Guerra Fria fizeram-se já anunciar com a recusa soviética de retirar de território iraniano nas datas acordadas pelo Tratado de Teerão (Lenczowski, 1972: 47-50).

Os anos que se seguiram tornaram a competição entre as duas potências da Guerra Fria, em território iraniano, mais visível. Em 1951, após a nacionalização da indústria petrolífera iraniana pelo Primeiro-ministro Mohammad Mosaddeq, os serviços secretos norte-americanos, instigados pelos parceiros britânicos, organizaram a

113 A Anglo-Persian Oil Company foi estabelecida em 1908, para explorar as reservas petrolíferas descobertas na então Pérsia. Em 1935 foi redenominada Anglo-Iranian Oil Company e em 1953 tornou-se na British Petroleum Company (BP). 
"operação Ajax", que levou à deposição do governo. Embora os EUA tenham mantido confiança política no Xá, tornava-se claro que este se tinha tornado numa figura distante e cada vez mais desligada da realidade do país. Durante as décadas que se seguiram, o Xá, tal como outros líderes no Médio Oriente, usou a ameaça comunista como um meio para conseguir assistência política, económica, financeira e militar dos EUA, usada principalmente contra os oponentes internos ao regime (Summitt, 2004: 562).

Durante o regime do Xá Muhammad Reza, o Irão estabeleceu uma aliança estratégica com os EUA e tornou-se o maior comprador de armas norte-americanas (Ramazani, 2004: 554). O apoio de Washington ao regime repressivo do Xá constituiu um forte incentivo para a deterioração da perceção popular sobre os EUA no Irão e, depois da revolução islâmica, foi um vetor central da política externa e doméstica iraniana. A história das relações entre os EUA e o Irão, até 1979, mostram a construção de uma aliança de necessidade, tendo em conta a convulsão das relações internacionais durante a Primeira e Segunda Guerras Mundiais e a consolidação de relações de clientelismo entre os dois estados durante a Guerra Fria (Gasiorowski, 1991; Ghaneabassiri, 2002: 170).

\section{A revolução islâmica: o período ideológico liderado por Khomeini}

Com a transição do poder político para as mãos dos clérigos Shi'itas e principalmente do fundador da República Islâmica, o Grande Aiatola Ruhollah Khomeini, deu-se início a uma profunda revolução que alteraria a face do Irão nas três décadas seguintes, com implicações profundas nas dinâmicas do Médio Oriente. Um dos legados mais duradouros do Imã Khomeini foi a estrutura institucional iraniana que emergiu do processo revolucionário. O estabeleci- 
mento de estruturas dominadas por clérigos, a par de estruturas de governo seculares e da posição de Líder Supremo, acima de todos, instituiu não só a legitimação de um governo religioso, como centralizou todas as decisões nas mãos do Imã. Arjomand (2009: 6) refere a "rotinização do carisma" do Líder Khomeini como um elemento central na construção da nova ordem constitucional iraniana, ao passo que Takeyh (2009: 2) sublinha a longevidade da sua visão na construção do futuro da República Islâmica do Irão (RII).

Khomeini estabeleceu-se como um jovem clérigo na cidade de Qom e, especialmente a partir da década de 1960, mostrou interesse pelo debate de questões públicas, apresentando uma visão política muito influenciada pelos grandes movimentos anticolonialistas e nacionalistas (Takeyh, 2009: 11-14). ${ }^{114}$ Khomeini revelou-se um clérigo influente, determinado a recuperar um lugar central para o Islão na vida pública iraniana. Para isso, denunciou a "submissão" do regime do Xá aos interesses norte-americanos e o abandono das práticas religiosas, que tinham até então formado parte integrante da vida pública iraniana. A mobilização conseguida por Khomeini, durante a década de 1960 e 1970, refletiu um desejo de mudança que seria canalizado para a consolidação do poder religioso, em detrimento do poder da monarquia. Esta tensão entre as duas bases da estrutura de poder iraniano (o Shi'ismo e a Monarquia) foi radicalmente alterada em favor da primeira. Daí que Khomeini estivesse profundamente comprometido com o estabelecimento de uma república islâmica, baseada numa forma teocrática de poder. A centralidade do governo religioso na visão do Imã ficou imortalizada no estabelecimento de um modelo político de jurisprudência religiosa (velayat-e faqib) que viria a ser aceite, não só pela comunidade religiosa no Irão, mas também pela população iraniana. Os seus discursos públicos e as suas estraté-

114 Para uma análise detalhada da visão ideológica de Khomeini ver Rajacc (1983). Ver também Arjomand (2009: 16-35). 
gias de mobilização da classe religiosa eventualmente levaram a que o Xá ordenasse primeiro a sua prisão e, em 1964, a sua deportação para o exílio, na Turquia. No ano seguinte, Khomeini estabeleceu-se em Najaf, no Iraque, onde desenvolveu o seu pensamento sobre a jurisprudência religiosa, que viria a ser divulgado de forma clandestina no Irão (Algar; Takeyh, 2009: 15-17). Conseguiu também consolidar um movimento de oposição nacional ao Xá, albergando diferentes forças políticas e religiosas sob a bandeira da revolução.

A resposta violenta do Xá ao descontentamento crescente na sociedade iraniana e as sucessivas e inconsequentes reformas revelaram os limites da monarquia em acomodar as reivindicações sociais e políticas iranianas (Bill, 1978: 324-329; Pollack, 2004: 137-140). Por sua vez, Khomeini consolidou a sua visão de uma república islâmica como alternativa à corrupção do regime vigente. No final de 1978 e até 16 de janeiro de 1979, quando o Xá abandonou o país, verificaram-se manifestações populares desafiando a lei marcial, greves gerais e mesmo dentro das forças armadas emergiram profundas divisões entre a geração mais velha, leal ao Xá, e as gerações mais novas fascinadas pela ideia de um governo religioso (Algar: 2010). Com efeito, o objetivo comum e imediato de remover o Xá foi a força maior que juntou elementos de todas as classes sociais, de todos os quadrantes intelectuais, movimentos religiosos e seculares (Katouzian, 2009: 21). O regresso do Imã a Teerão, a 1 de fevereiro de 1979, simbolizou o culminar da revolução e inaugurou o novo período de acomodação política e social, com profundas implicações na forma como a política externa do país passou a ser conduzida.

Com a adoção, no final de 1979, de uma nova Constituição instituindo um governo religioso, a RII tornou-se o primeiro estado a ter um governo islâmico. Será, pois, Khomeini quem irá definir as grandes linhas da política externa iraniana no período pós-revolucionário, quer com uma visão ideológica da nova missão da república islâmica, quer fazendo sentir o seu poder sobre os outros 
elementos do novo governo. Segundo o Líder Supremo, a revolução iraniana simbolizava apenas o começo do que deveria ser um movimento maior, comum a toda a humanidade, mas em especial a todos os muçulmanos. ${ }^{115}$ Subjacente a este princípio estão portanto três ideias centrais: a RII deveria ter um papel de charneira na exportação da revolução islâmica, principalmente no contexto do Médio Oriente; deveria procurar consolidar a unidade islâmica (principalmente entre Sunitas e Shi'itas) (Rajacc, 1983: 85); e seria necessário reconhecer que a falta de unidade entre muçulmanos se devia principalmente à presença de potências imperialistas no Médio Oriente, cujo objetivo era, não só explorar as riquezas da região, como evitar que o Islão se tornasse uma força relevante. Assim, emerge como parte crucial do discurso revolucionário e ideológico de Khomeini a criação de um arqui-inimigo da revolução, simbolizado pelos EUA e por Israel (Takeyh, 2009: 18-22).

A prevalência de um contexto ideológico e de grande conturbação durante o período revolucionário facilitou em grande medida a consolidação de uma imagem paranoica dos EUA. A crise dos reféns da embaixada norte-americana em Teerão ilustrou esse receio profundo de que Washington interferisse na revolução iraniana (Pollack, 2004: 153-159; Takeyh, 2009: 36-46). Este episódio acabou por marcar a imagem que as duas nações têm de si próprias e do outro. A 4 de novembro de 1979 iniciaram-se 444 dias de ocupação da embaixada norte-americana em Teerão por um grupo de estudantes, reivindicando o fim dos planos norte-americanos de subversão da revolução sagrada. Embora a tomada da embaixada tivesse como objetivo a humilhação do "Grande Satã" e a afirmação de uma nova relação

115 "The Iranian Revolution is not exclusively that of Iran, because Islam does not belong to any particular people. Islam is revealed for mankind and the Muslims, not for Iran... An Islamic movement, therefore, cannot limit itself to any particular country, not even to the Islamic countries; it is the continuation of the revolution by the prophets». Sermão proferido por Khomeini, a 2 de novembro de 1979, citado em Rajacc (1983: 82). 
de poder, esta crise ilustrou também as dinâmicas internas de luta pelo poder. No imediato contexto pós-revolucionário, uma aliança de partidos de esquerda e liberais estabeleceu um novo governo liderado por Mehdi Bazargan, com o apoio dos clérigos. A par do governo, foi estabelecido o Conselho Revolucionário, sendo composto por clérigos próximos de Khomeini, por líderes políticos próximos de Bazargan e elementos das forças armadas. As decisões políticas que guiaram a RII no período pós-revolucionário viriam a ser o resultado do confronto entre uma visão conciliadora de Bazargan, nomeadamente no que toca ao relacionamento com os EUA, e a visão radical que o Conselho Revolucionário e Khomeini viriam a promover, incluindo o seu apoio implícito às ações dos estudantes.

Com efeito Bazargan mostrou-se favorável à manutenção de relações com os EUA, embora o seu objetivo imediato fosse fazer regressar a RII a uma política de equilíbrio, pondo fim à aliança com os EUA. Para esse efeito, a RII retirou-se da Organização do Tratado do Médio Oriente, que havia sido criada em 1955, e cancelou os acordos de defesa que o Xá tinha estabelecido com Washington (Ramazani, 1989: 204-205). Apesar destas decisões, o desejo de acomodação com os EUA foi visto pelos clérigos como um sinal de fraqueza e que contrariava o objetivo maior de Khomeini de estabelecer uma ordem mundial islâmica. Para além disso, o facto de a administração Carter ter admitido que o Xá entrasse nos EUA para tratamento médico, apenas reforçou a ideia de que a revolução estava em perigo. Segundo Ramazani (1989: 206-210), este período viu a política externa iraniana ser dividida em dois blocos centrais: por um lado os nacionalistas realistas, como Bazargan, viam a independência do Irão como um aspeto central, mas que deveria ser conseguida mantendo relações de equilíbrio com as duas superpotências e com os seus vizinhos; por outro lado, os idealistas revolucionários viam o Islão como a razão maior para a política externa do país e, como tal, todos os outros objetivos deveriam ser subjugados ao princípio 
da exportação da revolução e da criação de um Golfo Pérsico sem influência norte-americana.

Os reféns foram libertados já em 1981, numa altura em que o poder de Khomeini e dos clérigos estava consolidado através de uma nova ordem constitucional. No entanto, em 1980 teve início um dos principais acontecimentos na vida pós-revolucionária do Irão: a guerra com o Iraque, que durou até 1988 e terminou com um armistício negociado pelas Nações Unidas. As razões que levaram Saddam Hussein a invadir o Irão a 22 de setembro de 1980 são multifacetadas, incluindo disputas territoriais, políticas e religiosas (Gregory Gause III, 2002). Foi uma combinação de oportunidade e receio que levou Saddam Hussein a iniciar a guerra: oportunidade de enfraquecer ainda mais o seu inimigo histórico e conquistar parte do seu território, numa altura em que o seu governo se encontrava fragilizado; e receio de que a nova ideologia, protagonizada por Khomeini, tivesse um impacto visível na minoria Shi'ita no Iraque, destabilizando o regime secular Bah'ista (Takeyh, 2009: 82-87). Embora, no início da guerra, o Irão se apresentasse numa situação de aparente desvantagem, os novos líderes transformaram o conflito numa ferramenta de consolidação do seu poder. A guerra ganhou contornos de uma cruzada, representando uma oportunidade para o povo iraniano demonstrar «não só o ardor nacionalista, mas também a sua devoção religiosa" (Takeyh, 2009: 89).

A guerra entre o Irão e o Iraque foi uma das mais longas e violentas da história do Médio Oriente. Foi uma guerra total, em que ambos os lados usaram todo o seu poderio militar, humano e financeiro (Hooglund, 1987: 13). Para além das implicações domésticas, a guerra teve um impacto profundo nas relações do Médio Oriente e acabou por se internacionalizar no contexto da Guerra Fria (Takeyh, 2009: 101-107). O Irão viu-se isolado e marginalizado pelo conflito, após a decisão dos estados do Conselho de Cooperação do Golfo (CCG), todos árabes, e dos EUA, Alemanha, França e Reino 
Unido de apoiarem o Iraque (Taremi, 2003: 386). Com efeito as políticas expansionistas da RII no Médio Oriente, através da criação de movimentos armados como o Hezbollah no Líbano ou o Hamas na Palestina criaram uma suspeita profunda, não só entre os seus vizinhos, como a nível internacional. No contexto da guerra com o Iraque, estes ressentimentos foram um motivo forte para isolar o regime islâmico.

A RII manteve, nessa altura, relações próximas com Moscovo e com Pequim (Hickey, 1990), bem como com dois aliados improváveis, recorrendo a uma política de alianças pragmáticas: Síria e Israel. Para o regime de Damasco, a ajuda ao Irão representava uma forma de combater a presença norte-americana, enquanto para Teerão, a Síria representava uma fonte de armas importante, bem como um sinal de divisão na solidariedade árabe, que poderia trazer dividendos para Teerão (Takeyh, 2009: 74-79). O apoio de Israel é ainda mais inesperado, tendo em conta as declarações dos novos líderes revolucionários contra o "Pequeno Satã» e a sua denúncia da criação do estado de Israel, como uma imposição das potências imperialistas, que deveria ser terminada. No entanto, para ambos os estados as exigências da guerra e os cálculos de longo prazo sobrepuseram-se ao fervor religioso ou ideológico. Com efeito, Teerão necessitava urgentemente de apoio militar israelita que colmatasse a falta de acesso a novas armas ou a meios de reparar o arsenal iraniano de fabrico ocidental. Para Israel, o apoio a Teerão era uma escolha tática com vista a garantir que Saddam Hussein não consolidasse o seu domínio no Médio Oriente (Takeyh, 2009: 61-69). A dada altura, os próprios EUA recorreram a contactos com os iranianos, para que fossem libertados reféns no Líbano, em troca de armas (Parsi, 2007). O que ficou conhecido como o escândalo Irão-Contras foi, porventura, o evento mais demonstrativo do grande pragmatismo e oportunismo nas relações externas do Irão, mas também de Israel e dos EUA. 
O fervor ideológico dos anos da revolução e da liderança de Khomeini marcaram as relações externas iranianas na década de 1980, promovendo a exportação da revolução, principalmente para o Golfo Pérsico e o Médio Oriente e consolidando uma aliança islâmica que pudesse ser um contraponto à bipolaridade. No entanto, e como vimos, o pragmatismo foi uma constante, exigindo cálculos ocasionais que contrariavam os ensinamentos religiosos e ideológicos. Os traços centrais deste período, marcado pelo isolamento internacional do Irão e pela consolidação das suas políticas de intervenção e destabilização regional, permaneceram nas décadas seguintes. Foi, no entanto, a RII a cortar laços com a comunidade internacional, profundamente desiludida com as suas políticas da acomodação face à utilização de armas químicas pelo Iraque de Saddam Hussein. Para os iranianos e os seus líderes tornou-se claro que, só dependendo de si mesmo, o Irão poderia sobreviver num contexto hostil. Estas tendências foram suavizadas durante a liderança de Rafsanjani, mas permanecem até hoje uma parte central da política externa iraniana.

\section{Abertura ao mundo: o período pragmático liderado por Rafsanjani}

O ano de 1989 representa um marco histórico também na vida política da RII. Nesse ano, Khomeini, procurando dar um novo impulso à revolução, anunciou uma fatwa contra Salman Rushdie, devido à publicação de Versículos Satânicos. ${ }^{116}$ Pouco tempo depois,

116 Uma fatwa é um edital religioso sobre a aplicação da lei islâmica em qualquer situação da vida de uma comunidade e é emitida por um clérigo ou autoridade religiosa. No caso de Salman Rushdie, foi lançada pelo Aiatola Khomeini, devido à alegada blasfémia e apostasia do seu romance "Versículos Satânicos» e continha uma sentença de morte por violação da lei islâmica. 
o Líder Supremo e arquiteto ideológico da revolução falecia, dando início a um processo de luta interna pelo poder entre as diferentes fações da vida política, económica, social e militar iranianas (Moslem, 2002; Siavoshi, 1992). Os apoiantes da revolução islâmica procuraram consolidar um status quo que lhes fosse favorável, com acesso a benefícios políticos e socioeconómicos. Segundo Alamdari (2005: 1290-1291), nesta fase consolidaram-se diversos centros de poder verticais e autónomos que facilitaram o desenvolvimento de relações de clientelismo, com profundas implicações para as reformas económicas e políticas que o novo Presidente, Akbar Hashemi Rafsanjani, procurou implementar depois de 1989.

Neste novo contexto, a nomeação de um novo Líder Supremo era uma prioridade. Presidente da República entre 1981 e 1989, Ali Khamenei foi então elevado à categoria de Aiatola e nomeado Líder Supremo pela Assembleia de Peritos. Com a revisão constitucional de 1989, foi abolido o cargo de Primeiro-ministro, criando um regime presidencialista, de liderança dupla, e foi estabelecido o poderoso Conselho de Segurança Nacional, com poderes reforçados em matéria de política externa. Uma vez resolvido o dilema imediato da sucessão de Khomeini, a RII precisava agora encontrar soluções para o avolumar de desafios que o contexto interno, regional e internacional colocava. Rafsanjani procurou iniciar uma era de reconstrução (Takeyh, 2009: 113), que permitisse reparar os danos causados pela devastadora guerra com o Iraque e legitimar o novo governo, com base em políticas sociais. Para isso, contudo, era necessário alterar as relações com os vizinhos do Golfo Pérsico e abrir novas possibilidades de relações comerciais com os países europeus e a União Soviética/Rússia, que permitissem ao Irão aceder a importantes créditos internacionais e reverter o estado de dependência absoluta da sua economia (Taremi, 2003: 388; Tarock, 1999). Embora as exigências práticas da reconstrução fossem um aspeto central da nova política de acomodação, a tensão entre pragmatis- 
mo e ideologia manteve-se visível, dando origem a acesos debates internos, sobre os perigos e as vantagens da cooperação com os EUA. Perante a existência de uma só superpotência, o Irão viu-se obrigado, também, a melhorar relações com diversos novos parceiros, não necessariamente muçulmanos, bem como a tentar forjar a sua presença em organizações regionais não dominadas pelo Ocidente (Herzig, 2004: 505; Ramazani, 1992: 401-403).

Com efeito, no novo contexto pós-Guerra Fria, Teerão viu-se obrigado a alterar a sua política externa, abandonando o princípio de «nem Ocidente, nem Oriente» e estabelecendo o princípio de "Norte e Sul» (Ramazani, 1992). Isto significava, abertura aos novos estados independentes do Cáucaso do Sul e da Ásia Central (Arjomand, 2009: 141-143; Herzig, 2004; Ramazani, 1992) e à Rússia. Apesar dos momentos de tensão entre Teerão e Moscovo, nomeadamente durante a invasão Soviética no Afeganistão (Milan, 2006: 235-246) e durante a guerra na Chechénia, os dois estados viram benefícios numa cooperação estratégica. Um dos objetivos centrais era limitar a presença norte americana no Golfo Pérsico e no Mar Cáspio (Lowe and Spencer, 2006: 40-43) e, desde o final da década de 1990, a cooperação nuclear passou a ser um aspeto central das suas relações. Teerão, com o apoio de Moscovo, desempenhou também o papel de mediador no conflito de Nagorno-Karabakh, entre a Arménia e o Azerbaijão, e na guerra civil que deflagrou no Tajiquistão. Perante a abertura do espaço da Eurásia, quer o Irão, quer a Turquia procuraram reforçar a sua presença, tendo por base uma abordagem pragmática e funcionalista. Com efeito, no início da década de 1990, os dois estados entraram em competição por influência nesta região, principalmente através da promoção de integração regional baseada em afinidades culturais e linguísticas (Calabrese, 1998; Herzig, 2004: 507).

No contexto do Golfo Pérsico, a nova liderança iraniana procurou alcançar dois objetivos centrais: conter o Iraque e reconciliar-se com 
os estados do CCG. O fim da guerra com o Iraque não resolveu as disputas territoriais entre os dois estados. Com efeito, a invasão iraquiana do Kuwait, em 1990, confirmou o entendimento de Teerão de que a liderança iraquiana representava o principal elemento desestabilizador na região. O Irão usou esta oportunidade para demonstrar o seu apoio ao pequeno estado árabe e exigir que o CCG denunciasse a invasão iraquiana (Ramazani, 1992: 396; Takeyh, 2009: 134). A subsequente primeira guerra do Golfo representou uma oportunidade para Teerão se afirmar como um ator empenhado na estabilidade regional, mas também trouxe ameaças claras. A primeira delas era a presença de tropas internacionais e principalmente norte-americanas no Golfo Pérsico. Para as fações radicais no Irão, o dever da república islâmica era denunciar e combater essa presença. Contudo, numa fase em que o Irão procurava normalizar a suas relações externas e integrar-se na economia mundial, as exigências ideológicas teriam de ser calibradas por interesses económicos e políticos. Um outro desafio foi a permanência de Saddam no poder e o perigo de desmembramento do estado iraquiano, especialmente nos territórios curdos e de maioria Shi'ita. Perante a oportunidade de apoiar a rebelião Shi'ita no Iraque, Teerão limitou o seu apoio a questões logísticas (Ramazani, 1992: 398; Takeyh, 2009: 136; Taremi, 2003: 390) e não investiu em destabilizar o país vizinho.

A melhoria de relações com os estados do CCG tinha como objetivos centrais reforçar a política de contenção do Iraque, melhorar o contexto económico iraniano e alterar favoravelmente os arranjos regionais de segurança. Para isso, as relações problemáticas de Teerão com a Arábia Saudita tinham de ser revistas. Em 1988, após a morte de mais de 400 peregrinos, entre eles perto de 300 iranianos, aquando das peregrinações anuais a Meca, as relações diplomáticas entre os dois países foram cortadas (Caryl, 2009). Durante a guerra com o Iraque, o Irão viu os preços do crude descerem após o aumento da produção saudita, num apoio claro de Riade a Saddam Hussein. 
No entanto, a questão que mais separa os dois estados é a parceria estratégica da Arábia Saudita com os EUA e, embora as relações diplomáticas tenham sido restabelecidas depois da primeira guerra do Golfo, as diferentes visões relativamente ao papel os EUA não foram reconciliadas. Efetivamente, para a RII o estabelecimento de um acordo de segurança no Golfo, que exclua os EUA e que inclua Teerão, é um objetivo central, mas irreconciliável com a perceção dos estados árabes do Golfo que veem os EUA como um aliado e uma garantia de segurança (Taremi, 2003: 390). Embora o resultado das políticas de aproximação e acomodação regionais de Rafsanjani tenha sido limitado, o contexto regional após a guerra do Golfo e com o fim da União Soviética era profundamente diferente, confirmando a RII como um ator regional incontornável.

Para Israel, este novo contexto regional tinha algumas desvantagens, nomeadamente a falta de um inimigo comum com os EUA. Após a derrota de Saddam, a Administração Bush lançou imediatamente o processo de paz Israelo-Árabe, que culminaria com os Acordos de Oslo. É neste contexto que a rivalidade com Teerão irá escalar para novos níveis. Segundo Parsi (2005: 261), Israel e o Irão acabaram por competir pelo mesmo vácuo de poder deixado com a derrota do Iraque. Após os acordos de paz com os estados árabes, ambos se encontravam em posição de se tornarem atores económicos centrais na região. Para além disso, o Irão, com a sua retórica antiocidental e anti-israelita, representava a ameaça necessária para manter a aliança com os EUA e para garantir apoio doméstico ao processo de paz em Israel. Para Teerão, a sua exclusão dos arranjos de segurança regionais e a política de isolamento seguida por Israel e os EUA exigiram uma presença mais visível que confirmasse o seu papel central na segurança regional. Nesse sentido, o Irão denunciou o processo de paz e renovou o seu apoio aos grupos militantes palestinianos e no Líbano, reforçando o seu objetivo de travar o processo de paz israelo-árabe. Embora even- 
tualmente esta política tenha rendido os seus frutos e Israel tenha alterado a sua posição face a Teerão, os danos nas relações externas do Irão com os países europeus e com os EUA foram devastadores. A denúncia de Teerão como um instigador de terrorismo islâmico fundamentalista e as notícias preocupantes sobre o seu programa nuclear pareciam reverter os resultados positivos da abertura inicial conseguida por Rafsanjani. Quando o Presidente Khatami chegou ao poder em 1997, o Irão encontrava-se num processo de mudança acelerada, exigindo reformas mais profundas do que Rafsanjani tinha sido capaz de fazer. A RII tinha também consolidado o seu programa nuclear com apoio russo e chinês e sofria, desde 1996, sanções norte-americanas, estabelecidas depois da adoção do Ato de Sanções Irão-Líbia.

\section{Diálogo civilizacional: o período reformista liderado por Khatami}

As eleições de 1997 marcaram um período fascinante na política doméstica do Irão, que teve também impacto na sua política externa. A chegada surpreendente do movimento reformista ao poder iniciou um processo de reforma que traduzia, em parte, uma nova realidade social do Irão, mas também uma rutura com a ideologia totalitária da revolução islâmica (Arjomand, 2009: 92). O processo de liberalização da sociedade iraniana iniciou-se, pois, com esta vitória: o número de jornais, de associações e Organizações Não Governamentais (ONG) registadas aumentou de forma exponencial; o respeito pelo estado de direito passou a ser uma prioridade assumida pelo novo Presidente (Arjomand, 2009: 93-94); e, no seu conjunto, o movimento procurou "reconceptualizar as relações entre os cidadãos e o estado, bem como entre a religião e a democracia» (Takeyh, 2009: 184). Embora o movimento reformista tenha sido 
em grande parte restringido nos resultados da sua ação, pela estrutura institucional que garantia aos órgãos religiosos a supervisão e direito de veto de todas as iniciativas legislativas do Presidente e do Parlamento, a imagem externa de RII alterou-se de forma positiva.

Durante a campanha eleitoral, a reintegração do Irão na comunidade internacional e a reconciliação com os seus vizinhos figuraram proeminentemente nos discursos de Khatami. Uma das suas prioridades foi promover um diálogo civilizacional, apoiado na coexistência, em vez da rivalidade. Foi uma mudança de discurso radical, em comparação com os candidatos conservadores, apoiados pelas estruturas religiosas, que apostavam na denúncia do ocidente como fonte de decadência e imperialismo (Takeyh, 2009: 182-187). Khatami procurou também estabelecer diálogo com os EUA e, logo em janeiro de 1998, após a sua eleição, deu uma entrevista exclusiva à cadeia televisiva CNN, sublinhando os interesses partilhados entre o Irão e os EUA, embora reconhecendo que se mantinham graves desentendimentos. O seu desejo de mostrar uma nova face da RII tinha sido já demonstrado aquando da sua participação no encontro da Organização da Conferência Islâmica (OCI), em dezembro de 1997, quando afirmou "O verdadeiro diálogo só será possível quando os dois lados tiverem consciência das suas raízes e da sua identidade» (citado em Ansari, 2006: 160).

Podemos, pois, afirmar que o movimento reformador, liderado por Khatami, procurou ao nível interno transformar a RII num estado democrático, preocupado não apenas com a missão universal da revolução islâmica, mas com a reforma das estruturas domésticas. Por outro lado, o novo discurso conciliador e os gestos de boa vontade do novo Presidente procuraram mostrar ao mundo outra face do RII, facilitando o diálogo e, porventura, criando novas oportunidades de desenvolvimento económico e político. No entanto, esta abordagem teve dois problemas centrais, que ilustram a ligação próxima entre as 
dinâmicas internas e as opções de política externa (e vice-versa). Em primeiro lugar, a reação norte-americana às aberturas do Presidente Khatami foi confusa, demonstrando falta de preparação e entrou em choque com a sua mensagem de diálogo, numa altura em que a Administração Clinton mantinha uma política de "contenção dupla" (do Irão e do Iraque), no Médio Oriente. Apenas a Secretária de Estado, Madeleine Albright, emitiu um pedido formal de desculpas, em março de 1998, pelo envolvimento norte-americano no golpe de estado que retirou o Primeiro-ministro Mosaddeq do poder em 1951 (Ansari, 2006: 161).

Em segundo lugar, a política de "dissuasão, respeito mútuo e diálogo» de Kahtami (Takeyh, 2009: 198), apoiada inicialmente pelo Líder Supremo, Khamenei, traduziu-se na melhoria de relações principalmente com a Arábia Saudita e os vizinhos do Golfo, e, em 1999, Khatami tornou-se o primeiro Presidente iraniano a visitar Riade. A esta visita seguiram-se uma série de acordos bilaterais e uma colaboração próxima com a Arábia Saudita dentro da OPEC. Khatami anunciou também que o Irão estaria disposto a respeitar um acordo de paz que os palestinianos aceitassem (neste caso, uma solução de dois estados) o que preconizava um reconhecimento implícito do estado de Israel. Na Europa, a eleição de Khatami foi vista como uma possibilidade real de liberalização das políticas domésticas, a que a União Europeia respondeu, instituindo uma nova política de «envolvimento construtivo» em vez de um «diálogo crítico». Houve uma série de visitas bilaterais sem precedente, com o Presidente Khatami a ser recebido em diversas capitais europeias. No entanto, embora a nova abordagem de Khatami fosse vista com bons olhos pelos europeus, isso não se traduziu em benefícios concretos, nomeadamente na área económica, trazendo descrédito à agenda do Presidente. As forças reacionárias rapidamente se organizaram para minar a sua autoridade e, por sua vez, isso teve um impacto visível na imagem externa de Khatami e da RII. 
Os acontecimentos de 11 de setembro de 2001 marcaram a política externa iraniana de forma radical. A reação inicial dos líderes iranianos foi de apoio aos EUA, disponibilizando assistência no combate ao regime Talibã, no Afeganistão. Este alinhar de interesses foi visto com desconfiança pelas diferentes forças nos dois países, principalmente entre os grupos mais radicais (os reacionários no Irão e os neoconservadores nos EUA) (Ansari, 2006: 164-165). Efetivamente, o Irão tinha tentado criar, desde a revolução islâmica, uma esfera de influência ideológica no Afeganistão, procurando mobilizar as populações Shi'itas, durante os anos de ocupação soviética (Milan, 2006: 236-239). Procurou inclusivamente influenciar os processos políticos neste país vizinho, criando uma alternativa política que lhe fosse próxima. Por isso, o interesse norte-americano em derrubar o regime Talibã foi visto de forma positiva em Teerão e as ligações iranianas à Aliança do Norte foram essenciais para que a coligação internacional, liderada pelos EUA, conseguisse alguns resultados positivos (Milan, 2006: 246-251). Às oportunidades de cooperação com os EUA no Afeganistão, os iranianos contrapuseram também os perigos de uma presença militar norte-americana no país vizinho, que viria a ser reforçada, em 2003, com a invasão do Iraque. Um sentimento de cerco (Ehteshami, 2004: 187; Milan, 2006: 248) e a perceção de que um arco de instabilidade estava em desenvolvimento nas suas fronteiras fizeram com que, durante a Administração Bush, não houvesse melhorias nas relações bilaterais.

Perante os desafios da guerra global contra o terrorismo e o novo contexto no Médio Oriente, a política de dissuasão, promovida pelo Presidente Khatami, tinha de ser agora cuidadosamente calibrada com uma cooperação pragmática com Washington. No entanto, o discurso do Estado da Nação, do Presidente George W. Bush, em janeiro de 2002, contrariou as aspirações de uma relação mais próxima, ao incluir o Irão no "eixo do mal». Até 2005, quando o Irão elegeu Mahmoud Ahmadinejad como novo Presidente, as preocupa- 
ções iranianas centraram-se em três grandes questões: manter uma política de envolvimento construtivo na estabilização e reconstrução do Afeganistão; procurar que os seus interesses estivessem representados na nova estrutura política iraquiana; e assegurar que os dois princípios basilares da sua política externa (garantir segurança interna e estabilidade regional) eram salvaguardados. É nesta ótica que o desenvolvimento do programa nuclear iraniano deve ser entendido, como uma forma de compensar o isolamento internacional e regional e de assegurar que a sua política de independência e autossuficiência são mantidas.

\section{Liderança regional: o período reacionário liderado por Ahmadinejad}

Apesar das importantes aberturas de Khatami ao mundo, no final dos seus dois mandatos, o Irão encontrava-se numa situação de grande fragilidade. A sobrevivência do regime estava sob ameaça direta da superpotência norte-americana, agora dedicada a combater a proliferação de armamentos nucleares através da promoção da democracia, e o seu papel regional estava gravemente debilitado com a presença reforçada do exército norte-americano no Iraque e no Afeganistão. A chegada de uma nova elite ao poder serviu para rever as prioridades da política externa iraniana. Os representantes da Nova Direita, conservadores reacionários liderados por Ahmadinejad, subiram ao poder com as eleições parlamentares de 2004 e presidenciais de 2005, apoiados pelas franjas mais conservadoras da elite clerical, pelos Guardiães da Revolução, em especial pela milícia paramilitar Basij, e, em última análise, pelo Líder Supremo Khamenei.

Esta era a geração dos veteranos da guerra Irão-Iraque, devotos do Islão e dos ideais da revolução, promovidos por Khameini. Na 
sua mensagem doméstica enalteceram a redistribuição de riqueza e a justiça social e prometeram uma era de prosperidade e equidade. Prometeram também o regresso às origens da revolução, denunciando os anteriores Presidentes como tendo corrompido o ideal de Khomeini e a presença de "inimigos internos» ao regime, que serviram de legitimação às suas políticas de terrorismo e violência contra os opositores políticos (Arjomand, 2009: 149-156; Takeyh, 2009: 223-227). Inaugurava-se assim um novo período, de delapidação do caráter democrático dos processos políticos no Irão, com o recurso às milícias Basij, para cometer fraude eleitoral, nas eleições presidenciais de 2005 e, como ficou claro, depois novamente em 2009 (Arjomand, 2009: 151; 165-171). Em termos da sua política externa, os novos líderes promoveram uma política baseada nos ideais islâmicos, de forte vertente nacionalista, que identificava os EUA como a potência opressora do mundo islâmico. Esta identificação entre muçulmanos permitiu que Ahmadinejad conseguisse, com algum sucesso, ligar a segurança iraniana, incluindo o desenvolvimento do seu programa nuclear, à segurança regional (Barzegar, 2010: 184). Para isso, manteve ativa a tradicional política de alianças, reforçando os laços com a Síria, o Hezbollah e o Hamas, promoveu uma retórica anti-Israelita feroz e fez do programa nuclear iraniano o símbolo da opressão dos EUA ao mundo islâmico.

O programa nuclear foi a principal questão na política externa da RII, durante os mandatos de Ahmadinejad, embora as origens do sonho nuclear iraniano remontem ao período do Xá, com apoio direto dos EUA e das potências europeias (Kibaroglu, 2006). A decisão de reativar o programa nuclear prendeu-se, principalmente, com a experiência trágica dos iranianos durante a guerra com o Iraque. Nesse período consolidou-se a noção de autossuficiência em termos de segurança (que a opção nuclear assegura) e a perceção de que o uso indiscriminado de agentes químicos e bacteriológicos pelo regime de Saddam tinha sido aceite pela comunidade internacional e, em 
última instância, tinha forçado o Irão a assinar o armistício (Takeyh, 2009: 244-245). Durante o final da década de 1980, Rafsanjani conduziu uma série de contactos, no Paquistão, Argentina e com A. Q. Khan do Paquistão, com vista a adquirir tecnologia nuclear, que os EUA e os parceiros europeus recusavam fornecer. Khatami continuou essa política e abordou a China e a Rússia, tendo conseguido um acordo com Moscovo para construir o reator nuclear de Bushehr. ${ }^{117}$ No final de década de 1990, verificava-se um novo ímpeto no desenvolvimento do programa nuclear, em parte apoiado em setores da elite iraniana com interesses diretos nesta área. O resultado deste novo impulso tornou-se público, em 2002, quando foi denunciada a existência de instalações secretas em Natanz e Arak, que não tinham sido divulgadas à Agência Internacional de Energia Atómica (AIEA). Iniciou-se então o processo de negociações entre os líderes iranianos, a AIEA, os EUA e os parceiros europeus.

Relativamente ao programa nuclear e ao seu impacto na política externa iraniana, iremos centrar-nos em duas questões: a importância dos arranjos internos de poder na postura da RII nas negociações com os parceiros internacionais; e os potenciais impactos que um Irão nuclear terá no contexto regional do Médio Oriente e nas relações com os EUA. A subida ao poder dos reacionários, em 2005, veio alterar a estratégia que Kahatami e Khamenei tinham delineado e cujo principal objetivo era manter o programa nuclear, evitando sanções do Conselho de Segurança das Nações Unidas (CSNU) (Arjomand, 2009: 202). Esta estratégia tinha trazido alguns resultados positivos, nomeadamente a assinatura do Acordo de Paris, em 2004, embora a falta de apoio dos EUA à iniciativa franco-anglo-germânica acabasse por se traduzir num triunfo para os reacionários, que viam o acordo como uma humilhação para a RII.

117 Para uma perspetiva completa das ambições nucleares iranianas ver Chubin (2006). 
Efetivamente, Ahmadinejad usou o programa nuclear iraniano como arma de propaganda e de promoção de orgulho nacional e do mundo Islâmico (Ehteshami and Zweiri, 2007: 98). Por seu lado, o Líder Supremo tentou manter a via do diálogo aberta com os europeus e, em 2006, os cinco membros permanentes do CSNU mais a Alemanha $(5+1)$ voltaram à mesa das negociações com o Irão. Embora o acordo proposto não tenha sido rejeitado pelo Presidente iraniano, a RII falhou os prazos estabelecidos e acabou por sofrer novas sanções. Durante 2007 e 2008, Ahmadinejad continuou o seu processo de afirmação interna, por vezes desafiando diretamente a autoridade do Líder Supremo. Em 2008, Khamenei procurou novamente persuadir o CSNU da sua posição central na definição da política externa da RII e do desejo do país de continuar negociações (Arjomand, 2009: 202-203). No entanto, com o aproximar das eleições presidenciais de 2009 e a contestação que se seguiu, foi o cartel liderado pelos Guardiães da Revolução que beneficiou da fragilização da posição do Presidente Ahmadinejad e do Líder Supremo, pondo fim a qualquer esperança de negociações. Finalmente, em junho de 2010, o CSNU aprovou um novo pacote de sanções ao Irão.

A segunda questão prende-se com as relações de um possível Irão nuclear com o Médio Oriente e os EUA. Com a saída do poder dos Talibã no Afeganistão e de Saddam Hussein no Iraque, o Irão é hoje um ator central no Médio Oriente. Outras potências regionais como a Arábia Saudita, o Egito ou mesmo a Turquia poderão sentir-se tentadas a iniciar a uma corrida aos armamentos, incluindo armas nucleares, para travar a hegemonia regional iraniana. Sem dúvida, os equilíbrios de poder na região seriam profundamente afetados por essa possibilidade (Kaye and Wehrey, 2007: 111). Para o estado de Israel, a possibilidade de o Irão adquirir armas nucleares, aliada à retórica antissemita e anti-israelita do Presidente Ahmadinejad, é um risco sem precedentes à sua segurança (Ehteshami and Zweiri, 2007: 109). Daí que os líderes israelitas mantenham a possibilidade 
de um ataque preventivo sobre o Irão, caso a diplomacia não produza resultados. Para os países do Golfo Pérsico, um confronto nuclear na região teria consequências catastróficas. Independentemente da forma como a região se adapta à possibilidade nuclear, a presença incontornável do Irão na política regional, incluindo a sua presença reforçada no Iraque, na Palestina, por via do Hamas, e no Líbano, após a vitória do Hezbollah sobre Israel, em 2006, deixa adivinhar um processo de afirmação internacional que os EUA terão de reconhecer. A abertura do Presidente Obama à normalização de relações deverá, pois, ser entendida como um passo importante nesse reconhecimento, embora se adivinhem muitas dificuldades.

\section{Distensão e pragmatismo: o Irão do Presidente Rouhani}

A eleição de $11 .^{\circ}$ presidente iraniano, Hassan Rouhani, em junho de 2013, marcou uma importante viragem na perceção internacional da RII, apesar das claras linhas de continuidade. Rouhani afirmou-se como o candidato consensual do campo reformista, apresentando uma plataforma moderada e que procurava distanciar-se de alguns elementos mais conservadores associados ao anterior regime. $\mathrm{O}$ facto de as eleições terem tido uma forte afluência ( $72 \%$, segundo dados oficiais), depois dos problemas profundos levantados no processo eleitoral de 2009, reforçou a mandato popular de Rouhani, eleito à primeira volta com $50.71 \%$ dos votos. Como afirma Tabrizi (2013), "é provável que Rouhani tenha conseguido mobilizar da melhor forma o sentimento pró-moderação e o desejo de pragmatismo e mudança gradual, quer na política interna quer na política externa do país”. Assim, mais do que conseguir um mandato com vista a alterações profundas nas dinâmicas internas e externas do país, a eleição do Presidente Rouhani deve ser entendida como uma oportunidade de capitalizar a sua vasta experiência dentro do sistema para benefício 
do país, incluindo através das suas relações externas. Rouhani é um clérigo com importantes ligações ao sistema político iraniano e ao Líder Supremo Khamenei, participou em diversas importantes instituições nacionais, nomeadamente no Conselho Supremo de Segurança Nacional, e foi também o responsável pelas negociações do programa nuclear iraniano, entre 2003 e 2005, mantendo uma vasta rede de contactos diplomáticos e políticos a nível regional e internacional.

Refletindo a sua larga experiência diplomática, a política externa assumiu um destaque pouco usual nos debates presidenciais que animaram a campanha eleitoral, sendo um dos elementos centrais da campanha do Presidente Rouhani. Ficou claro que, para o novo governo, a melhoria da situação interna económica e social do Irão está profundamente ligada a alterações estratégicas na relação entre a RII e os parceiros internacionais (Shanahan, 2015). Assim, o primeiro passo passava por diminuir o isolamento internacional imposto à RII, nomeadamente devido ao programa nuclear. Uma imagem de moderação e abertura ao diálogo, contrastante com o estilo mais acrimonioso do anterior presidente, facilitaria esta abordagem. Efetivamente, nos primeiros anos da presidência de Rouhani, são já visíveis importantes avanços nas negociações sobre o programa nuclear iraniano e nas relações com os EUA e os parceiros europeus (Norman, 2015). Contudo, o isolamento iraniano está também ligado às suas políticas regionais no Médio Oriente, nomeadamente no conflito sírio e no Iraque. As alterações profundas em curso na região na última década reforçaram a posição iraniana como um ator chave, quer enquanto potencial parceiro dos EUA na estabilização da região, quer enquanto força desestabilizadora. No Iraque, os líderes iranianos veem uma oportunidade única de evitar o ressurgimento de uma força estruturante da região e têm procurado simultaneamente acomodar as forças moderadas sunitas nas estruturas de poder e apoiar as milícias shi'itas garantindo controlo, quer sobre o processo político, quer sobre as dinâmicas militares (Takeyh, 2014). Na Síria, 
o apoio iraniano às milícias shi'itas e do Hezbollah, que combatem a favor do Presidente Bashar Al-Assad, tem sido um elemento prolongador do conflito que ameaça destabilizar o Médio Oriente de forma permanente. Assim, para as monarquias árabes sunitas da região, uma possível aproximação entre o Irão e as forças ocidentais, com base em avanços no programa nuclear e no desejo de cooperação na estabilização regional do Médio Oriente, deve ser cuidadosamente ponderada e ter em conta as múltiplas táticas empregues pelos líderes iranianos na consolidação da sua posição regional.

Para o novo Presidente, ficou claro desde o início que a recuperação da situação económica do país está profundamente ligada quer à sua estabilidade interna, quer à sua afirmação regional. Como sublinha Maloney (2014) o Presidente "tem articulado uma visão da segurança nacional onde a força económica é uma parte integral do poder nacional" iraniano. A atual situação iraniana oferece importantes possibilidades mas enormes fragilidades, em diferentes níveis de atuação. Em primeiro lugar, o alívio das sanções internacionais significaria um crescimento imediato da economia iraniana, altamente dependente dos recursos petrolíferos. Com a queda do preço internacional do petróleo nos últimos meses, os esforços de reforma económica, incluindo de diversificação da economia iraniana, revelam-se insuficientes (FMI, 2014), mantendo a pressão popular sobre o novo governo para que reverta a situação de declínio social do país. Assim, o sucesso das negociações nucleares é crucial para o novo governo, não apenas pelo simbolismo que o programa nuclear adquiriu para o prestígio internacional do Irão, nomeadamente junto das forças mais conservadoras do país, mas também para evitar novas rondas de sanções com devastadores resultados económicos e consequentemente políticos. Em segundo lugar, a afirmação regional iraniana e a necessidade dos EUA conseguirem resultados positivos no Médio Oriente têm feito com que o sucesso das negociações nucleares seja uma prioridade para ambas 
as partes. A ligação entre os dois elementos é um risco, mas caso seja bem-sucedida permitiria aos líderes iranianos inaugurar uma fase de influência regional que poderia ir para além das questões sectárias e militares e beneficiar de desenvolvimentos económicos regionais. Por fim, um elemento de incerteza prende-se com a idade avançada do atual Líder Supremo, Ayatollah Ali Khamenei, e os seus conhecidos problemas de saúde que exigirão mudanças na cúpula de decisão do país. Pelo poder amplo desta figura institucional, esta escolha é sempre de grande delicadeza e poderá significar um reforço das estratégias implementadas pelo governo ou uma reversão de algumas destas abordagens.

\section{Conclusões}

A política externa iraniana tem sido construída com base em dois pilares essenciais: pragmatismo e ideologia. Isso traduziu-se, inicialmente, numa tensão estruturante entre a Monarquia e o Islão, que a revolução de 1979 fez pender em favor do último. Tal como a maior parte dos estados, o Irão procura salvaguardar o que considera serem os seus interesses nacionais, tendo em conta um forte sentimento nacionalista persa. Isto tem-se traduzido numa política externa flexível e em constante refluxo. A perceção de estar inserido num contexto regional e internacional desfavorável, tem favorecido uma política de alianças e acomodação, quer com os vizinhos do Golfo Pérsico, quer com os EUA. No entanto, as estruturas internas de poder e a clara dimensão ideológica trazida pela revolução islâmica têm permitido que uma visão conservadora e reacionária tenha tido uma presença constante na política externa iraniana, antagonizando os EUA e Israel. As forças pragmáticas e reformadoras têm encontrado grandes dificuldades para justificar uma abordagem diferente, tendo em conta a profunda idealização do papel da RII no mundo. 


\begin{tabular}{|l|}
\hline Quadro 1. \\
\hline Fontes na internet \\
\hline Página do Presidente da República Islâmica do Irão, http://www.president.ir/en/ \\
\hline Página no Líder Supremo do Irão, http://www.leader.ir/langs/en/ \\
\hline Página do fundador da revolução islâmica, Imã Khomeini, http://en.imam-khomeini.ir/ \\
\hline Agência noticiosa iraniana (IRNA), http://www.irna.ir/en/ \\
\hline Council of Foreign Relations, http://www.cfr.org/region/iran/ri357 \\
\hline Brookings, http://www.brookings.edu/research/topics/iran \\
\hline
\end{tabular}

\begin{tabular}{|l|}
\hline Quadro 2. \\
\hline Leituras recomendadas \\
\hline $\begin{array}{c}\text { Takeyh Ray (2009) Guardians of the Revolution. Iran and the world in the age of the Ayatollahs. } \\
\text { Oxford: Oxford University Press. }\end{array}$ \\
\hline $\begin{array}{c}\text { Pollack, K. (2004) The Persian Puzzle: The Conflict between Iran and America. Nova Iorque: } \\
\text { Random House. }\end{array}$ \\
\hline Shirin Hunter (1992) Iran After Khomeini. Nova Iorque: Praeger. \\
\hline $\begin{array}{l}\text { Ehteshami, A. and Zweiri, M. (2007) Iran and the rise of Its neoconservatives: The Politics of } \\
\text { Tehran's Silent Revolution. London: Tauris. }\end{array}$ \\
\hline $\begin{array}{l}\text { Chubin, S. (2006) Iran's Nuclear Ambitions. Washington D.C.: Carnegie Endowment for Inter- } \\
\text { national Peace. }\end{array}$ \\
\hline
\end{tabular}

\begin{tabular}{|l|}
\hline Quadro 3. \\
\hline Questões para reflexão \\
\hline Quais as principais razões que conduziram à Revolução Islâmica de 1979, no Irão? \\
\hline Que linhas centrais guiam a política externa iraniana no período pós-revolucionário? \\
\hline $\begin{array}{c}\text { De que forma as dinâmicas de política interna afetam as opções de política externa no Irão? } \\
\text { Dê exemplos ilustrativos. }\end{array}$ \\
\hline $\begin{array}{c}\text { Quais os motivos que levaram a RII a iniciar o seu programa nuclear? E de que forma isso } \\
\text { afetou as suas relações com os EUA? }\end{array}$ \\
\hline $\begin{array}{c}\text { Qual a abordagem da RII para a segurança no Golfo Pérsico e Médio Oriente? E de que forma } \\
\text { é ilustrativa dos princípios basilares da sua política externa? }\end{array}$ \\
\hline
\end{tabular}

\section{Bibliografia}

Alamdari, Kazem (2005) "The Power Structure of the Islamic republic of Iran: transition from populism to clientelism, and militarization of the government", Third World Quarterly, 26(8), 1285-1301.

Algar, Hamid (2010) «Imam Khomeini: A Short Biography». [http://www.al-islam. org/imambiography/]. (consultado a 5 de junho de 2010). 
Ansari, Ali M. (2006) "Iran and the US in the Shadow of 9/11: Persia and the Persian Question Revisited", Iranian Studies, 39(2), 155-170.

Arjomand, Saïd A. (2009) After Khomeini. Iran under his successors. Nova Iorque: Oxford University Press.

Barzegar, Kayhan (2010) «Iran's Foreign Policy Strategy after Saddam», The Washington Quarterly, 33(1), 173-189.

Bill, James A. (1978) "Iran and the Crisis of '78", Foreign Affairs, 57(2), 323-342.

Calabrese, John (1998) "Turkey and Iran: Limits of a Stable Relationship", British Journal of Middle Eastern Studies, 25(1), 75-94.

Caryl, Christian (2009) "The Hajj", Foreign Policy, 20 novembro. [http://www. foreignpolicy.com/articles/2009/11/20/reality_check_the_hajj] (consultado a 28 de junho de 2009).

Chehabi, Houchang E. (1998) "The Pahlavi period», Iranian Studies, 31(3), 495-502.

Chubin, Shaharam (2006) Iran's Nuclear Ambitions. Washington D.C.: Carnegie Endowment for International Peace.

Ehteshami, Anoushiravan (2004) «Iran's International Posture after the Fall of Baghdad", The Middle East Journal, 58(2), 179-194.

Ehteshami, Anoushiravan e Zweiri, Mahjoob (2007) Iran and the rise of its neoconservatives: The Politics of Tehran's Silent Revolution. Londres /Nova Iorque: I.B.Tauris.

Eshraghi, F. (1984) “Anglo-Soviet Occupation of Iran in August 1941", Middle Eastern Studies, 20(1), 27-52.

FMI (2014) «Islamic Republic of Iran», IMF Country Report, 14/93.

Frye, Richard N. (1996) The Golden Age of Persia: The Arabs in the East. Nova Iorque: Barnes \& Noble.

Gasiorowski, Mark (1991) US Foreign Policy and the Shab: Building a Client State in Iran. Ithaca: Cornell University Press.

Ghaneabassiri, Kamyar (2002) «U.S. foreign policy and Persia, 1856-1921", Iranian Studies, 35(1), 145-175.

Gregory Gause III, F. (2002) «Iraq's Decision to Go to War, 1980-1990", Middle East Journal, 56(1), 47-70.

Herzig, Edmund (2004) "Regionalism, Iran and Central Asia», International Affairs, 80(3), 503-517.

Hickey, Dennis. v. V. (1990) "New Directions in China's Arms for Export Policy: An Analysis of China's Military Ties with Iran", Asian Affairs, 17(1), 15-29.

Hooglund, Eric (1987) «Iran and the Gulf War", MERIP Middle East Report, Re-Flagging the Gulf, 148, 12-18.

Katouzian, Homa (2009) "The Iranian Revolution of February 1979", Viewpoints: The Iranian Revolution at 30, The Middle East Institute, 29 janeiro.

Kaye, Dalia. D. and Wehrey, Frederic. M. (2007) «A Nuclear Iran: The Reactions of Neighbours", Survival, 49(2), 111-128.

Kibaroglu, Mustafa (2006) "Good for the Shah, Banned for the Mullahs: The West and Iran's Quest for Nuclear Power", Middle East Journal, 60(2), 207-232. 
Lenczowski, George (1972) «United States' Support for Iran's Independence and Integrity, 1945-1959", Annals of the American Academy of Political and Social Science, 401, 45-55.

Lowe, Robert e Spencer, Claire (2006) (org) Iran, Its Neighbours and the Regional Crisis. A Middle East Programme Report. London: The Royal Institute of International Affairs.

Maloney, Suzanne (2014) «Rouhani Report Card: A Year of Economic Stabilization and Suspense", Markaz (blog), Brookings Institution, 19 agosto. [http://www. brookings.edu/blogs/iran-at-saban/posts/2014/08/07-rouhani-reportcard-iran-economy-sanctions-oil[ (consultado a 14 de março de 2015).

Milan, Mohsen M. (2006) "Iran's Policy towards Afghanistan", Middle East Journal, 60(2), 235-256.

Milani, Abbas (2009) "The Three Paradoxes of the Islamic Revolution in Iran", Viewpoints: The Iranian Revolution at 30, 29 janeiro, The Middle East Institute.

Moslem, Mehdi (2002) Factional Politics in Post-Khomeini Iran. Syracuse, NI: Syracuse University Press.

Norman, Laurence (2015) «Iran Talks Closer on One-Year Nuclear 'Breakout' Demand", Wall Street Journal, 4 março. [http://www.wsj.com/articles/iran-talks-closer-on-one-year-nuclear-breakout-demand1425476621] (consultado a 14 de março de 2015).

Parsi, Trita (2005) «Israel-Iranian relations assessed: Strategic competition from the power cycle perspective», Iranian Studies, 38(2), 247-269.

Parsi, Trita (2007) Treacherous Alliance: The Secret Dealings of Israel, Iran, and the United States. New Heaven, Conn: Yale University Press.

Pollack, Kenneth (2004) The Persian Puzzle: The Conflict between Iran and America. Nova Iorque: Random House.

Rajacc, Farhang (1983) Islamic Values and World View: Khomeini on Man, the State and International Politics. Nova Iorque: University Press of America.

Ramazani, R. K. (1989) «Iran's Foreign Policy: contending orientations», The Middle East Journal, 43(2), 202-217.

Ramazani, R. K. (1992) "Iran's Foreign Policy: Both North and South", The Middle East Journal, 46(3), 393-412.

Ramazani, R. K. (2004) «Ideology and Pragmatism in Iran's Foreign Policy», The Middle East Journal, 58(4), 549-559.

Shanahan, Rodger (2015) "Iranian foreign policy under Rouhani», Analysis, Lowy Institute for International Policy, fevereiro.

Siavoshi, Susan (1992) "Factionalism and Iranian Politics: The Post-Khomeini Experience", Iranian Studies, 25(3/4), 27-49.

Summitt, April R. (2004) "For a White Revolution: John F. Kennedy and the Shah of Iran", Middle East Journal, 58(4), 560-575.

Tabrizi, Aniseh B. (2013) «Elections in Iran and Its Foreign Policy», Oxford Research Group, 4 julho. [http://www.oxfordresearchgroup.org.uk/publications/articles_ multimedia/elections_iran_and_its_foreign_policy_1] (consultado a 14 de março de 2015). 
Takeyh, Ray (2014) «Iran's Destabilizing Role in the Middle East», Prepared Statement Before the Foreign Affairs Committee, United States House of Representatives, 16 julho.

Takeyh, Ray (2009) Guardians of the Revolution. Iran and the World in the Age of the Ayatollahs. Nova Iorque: Oxford University Press.

Taremi, Kamran (2003) "Iranian perspectives on Security in the Persian Gulf», Iranian Studies, 36(3), 381-391.

Tarock, Adam (1999) "Iran-Western Europe Relations on the Mend", British Journal of Middle Eastern Studies, 26(1), 41-61. 